\title{
Experimental research on fatigue property of steel rubber vibration isolator for offshore jacket platform in cold environment
}

\author{
Yongjun $\mathrm{Xu}^{\mathrm{a}, *}$, Yubiao Liu ${ }^{\mathrm{a}}$, Changzhen Kan ${ }^{\mathrm{a}}$, Zhonghan Shen ${ }^{\mathrm{a}}$, Zhongmin Shi ${ }^{\mathrm{b}}$ \\ a Institute of Mechanics, Chinese Academy of Sciences, Beijing 100190, PR China \\ b China National Offshore Oil Corporation Research Center, Beijing 100027, PR China
}

\section{A R T I C L E I N F O}

\section{Article history:}

Received 12 October 2006

Accepted 8 February 2009

Available online 21 February 2009

\section{Keywords:}

Jacket offshore platform

Steel rubber bearing

Steel rubber vibration isolator

Vibration isolation

Vibration-reduction effectiveness analysis

Fatigue property

Cold environmen

\begin{abstract}
A B S T R A C T
Jacket platform is the most widely used offshore platform. Steel rubber vibration isolator and damping isolation system are often used to reduce or isolate the ice-induced and seismic-induced vibrations. The previous experimental and theoretical studies concern mostly with dynamic properties, vibration isolation schemes and vibration-reduction effectiveness analysis. In this paper, the experiments on steel rubber vibration isolator were carried out to investigate the compressive properties and fatigue properties in different low temperature conditions. The results may provide some guidelines for design of steel rubber vibration isolator for offshore platform in a cold environment, and for maintenance and replacement of steel rubber vibration isolator, and also for fatigue life assessment of the steel rubber vibration isolator.
\end{abstract}

(c) 2009 Elsevier Ltd. All rights reserved.

\section{Introduction}

Among the various types of offshore structures, the steel jacket platform is the most common in use, with multi-functions for oil exploration, drilling as well as for production. Conventionally, such platforms operate up to a depth of about $100-150 \mathrm{~m}$. They are usually built from tubular steel members. These structures have a very short vibration period ranging from 2 to $8 \mathrm{~s}$. Apart from the operational loads, they also subject to environmental loads such as wind, wave, ice and earthquake loads.

The safety of structures can usually be ensured by increasing their stiffness so as to shift the natural frequencies away from the resonating frequencies. However, this approach is generally costly, involving excessive construction materials. An alternate approach is to implement a passive and/or active control mechanism to regulate the structural motion as desired (Garcia and Soong, 2002). Passive control devices do not require external energy but with some inherent limitations. On the other hand, an active control mechanism can be effective over a wide frequency range with the desired reduction in the dynamic response. The active control approach is the current concern of many researchers and there are several attempts exploring its applications to offshore structures. Responses of offshore platforms with an actively tuned mass damper installed have been studied by Kawano (1993) and Kawano and Venkataramana (1992) and it is shown that such

\footnotetext{
* Corresponding author.

E-mail address: yjxu@imech.ac.cn (Y. Xu).
}

mechanism is quite effective in reducing the response of platforms due to wave loading. Lee (1997) demonstrated the effectiveness of mechanical dampers using stochastic analysis for offshore platform. Abdel-Rohman (1996) studied the applications of certain active and passive control mechanisms to reduce the dynamic response of steel jacket platforms due to wave loading. Suneja and Datta $(1998,1999)$ demonstrated the effectiveness of an active control system for articulated leg platforms in view of minimizing the wave-induced response. The effectiveness of the lateral vibration control was examined by Wang (2002) for wave-excited response of offshore platforms with magneto-rheological dampers. Mahadik and Jangid (2003) studied the response of offshore jacket platforms with an active tuned mass damper under wave loading. Although, there had been several studies on effectiveness of the active and passive control mechanisms in controlling the response of offshore platforms under wave loading, few studies had reported on the effectiveness of the passive control systems with added dampers in controlling the response of offshore platforms under a parametric variation of important system parameters and for comparative performance of dampers. Recently, Patil and Jangid (2005) developed passive control systems for vibration control of a certain offshore steel jacket platform using energy dissipation devices such as visco-elastic, viscous and friction dampers.

The horizontal components of earthquake ground motions or ice impacting motions are the most damaging to jacket offshore platforms. There are two primary mechanisms that cause damage. First one is related to inner-storey drifts, defined as the relative displacement between two adjacent floors, and the second one 
concerns with the absolute accelerations as a result of an earthquake or ice-impact. A design concept for reducing both the inner-storey drifts and floor accelerations combines the best aspects of the former two design philosophies. In fact, vibration isolation may have the desired results of reducing both floor accelerations and inner-storey drifts and therefore avoiding permanent damages to the structure itself and protecting what are in the structure. A base isolation system is an important class of passive seismic protective systems and is capable of reducing the horizontal seismic forces transmitted to structures (Tian and Wong, 1990; Wu and Samali, 2002; Woo-Jung et al., 1999). A mid isolation layer setting up between the jacket cap and deck of the offshore platform is capable of reducing the horizontal vibration aroused by ice, earthquake and wave forces. These methods have been successfully used in a practical platform JZ20-2NW. The steel rubber bearing is the most popular type of vibration isolator and is easy to manufacture. It can be made stiff in the vertical direction to take the vertical loads, and flexible in the horizontal direction to isolate the horizontal vibrations. This kind of vibration isolation is very effective in reducing high accelerations, or high frequency motions. The main aim of this isolation system/layer is to shift the natural frequencies of structures to a lower value and then to avoid structural resonance.

Most of the previous experimental investigations and theoretical studies were concentrated in the analysis of dynamic properties, vibration isolation schemes and vibration-reduction effectiveness. Yu and Wang (2005) and Ou et al. (2002) studied vibration-suppressed effectiveness of certain practical jacket platforms which installed both damping isolation systems and steel rubber bearings between the jacket cap and deck. Wu and Samali (2002) and Woo-Jung et al. (1999) analyzed vibrationreduction effectiveness by shaking table test of base isolation models where installed steel rubber bearings between the model structure and ground (shaking table). Liu et al. (2006) have investigated the fatigue characteristics in room temperature. In this paper, experiments on steel rubber bearings were carried out to investigate the compressive properties in different low temperatures and the fatigue property in a certain low temperature range. The results provide some guidance for design of steel rubber vibration isolator used for offshore platforms, and for maintenance and replacement of steel rubber vibration isolator, and a base of fatigue life assessment of the steel rubber vibration isolator using in a cold environment.

\section{The principle of vibration isolation and the corresponding isolator}

\subsection{Theoretical basis of vibration isolation}

In practice, it is customary for a continuous structure to be represented by a discrete model of order $n$, where $n$ is large enough to capture the necessary dynamic characteristics of the structure. Assume that a platform or a structure can be simplified as a lumped mass-spring-isolation layer model of a cantilever structure as shown in Fig. 1. If the problem is linear with nonproportional viscous damping, its motion is governed by the following differential equation.

$M \ddot{U}+C \dot{U}+K U=F(t)$

where $M, C$ and $K$ represent the mass, damping and stiffness matrices of size $n \times n$ respectively, and $U, \dot{U}, \ddot{U}$ and $F$ represent the displacement, velocity, acceleration and force vectors of order $n$, respectively. a

b

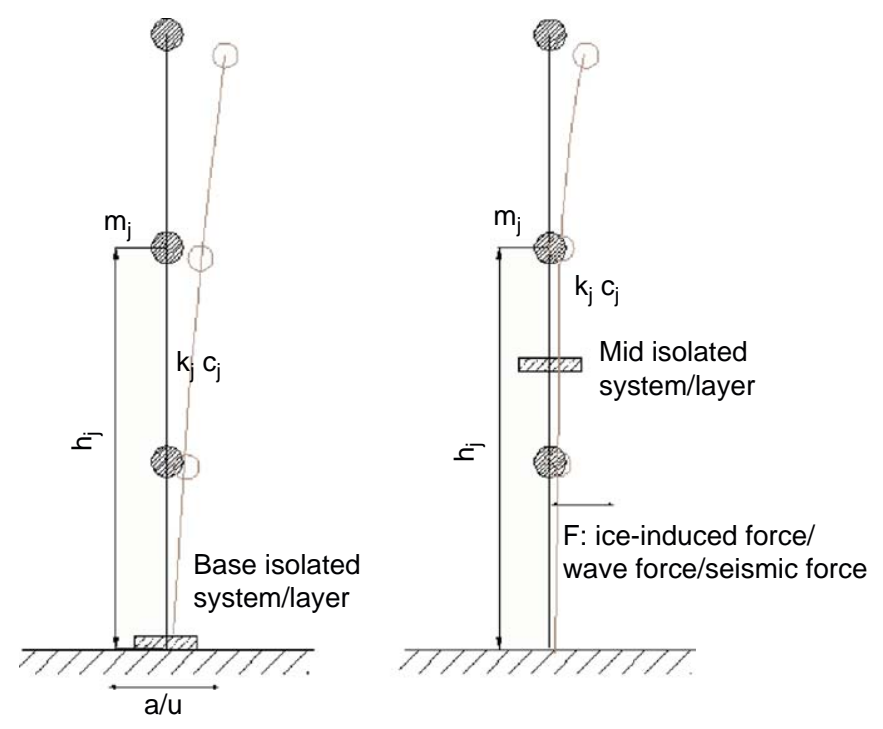

Fig. 1. Simplified isolation model.

The above equation can be written in the form of a state equation as

$\dot{X}=A X+B F$

where

$A=\left[\begin{array}{cc}0 & I \\ -M^{-1} K & -M^{-1} C\end{array}\right], \quad X=\left\{\begin{array}{cc}U^{T} & \dot{U}^{T}\end{array}\right\}^{T}$,

$\dot{X}=\left\{\begin{array}{ll}\dot{U}^{T} & \ddot{U}^{T}\end{array}\right\}^{T}, \quad B=\left[\begin{array}{c}0 \\ M^{-1}\end{array}\right]$

$A$ and $X$ represent, respectively, the system matrix and the state variable vector of order $2 n$. By solving the eigen-problem of the system matrix $A$, then the $n$ pairs of conjugate eigenvalues and eigenvectors of the structural system can be obtained. Further more, by making use of the $n$ nonconjugate eigenvalues and eigenvectors, the following eigenvalue matrix and modal vector matrix can be obtained.

$\lambda=\operatorname{diag}\left[\lambda_{1}, \lambda_{2}, \lambda_{3}, \ldots, \lambda_{n}\right], \quad \Phi=\left[\phi_{1}, \phi_{2}, \phi_{3}, \ldots, \phi_{n}\right]$

where $\lambda_{i}$ represents the $i$ th eigenvalue, while $\phi_{i}$ represents the natural modal vector with respect to $\lambda_{i}$. Similarly, the two conjugate matrices $\lambda^{*}$ and $\Phi^{*}$ can be also determined.

On the other hand, from Eqs. (2) and (3), it is seen that the system matrix $A$ involve the stiffness, damping and mass matrices. $M$ is a determinate matrix and $F$ is the environmental condition. Thus we can adjust $A$ by adjusting stiffness $K$ and damping $C$ to control the motions $X$ and $\dot{X}$, and control the eigenvalues and the natural modal vectors. The corresponding engineering method is to install a damper system or an isolation system/layer. Vibration isolation is a most effective method for the horizontal components of earthquake ground motions or ice impacting/wave force as shown in Fig. 1.

\subsection{Specifications and geometrical data of prototype steel rubber bearing}

Recently, the use of steel rubber bearing for the vibration isolation of offshore platform has become a common and well recognized method of providing protection against ice-induced, wave force and seismic damage. The geometric layouts of steel rubber bearing used for vibration isolation of offshore jacket 

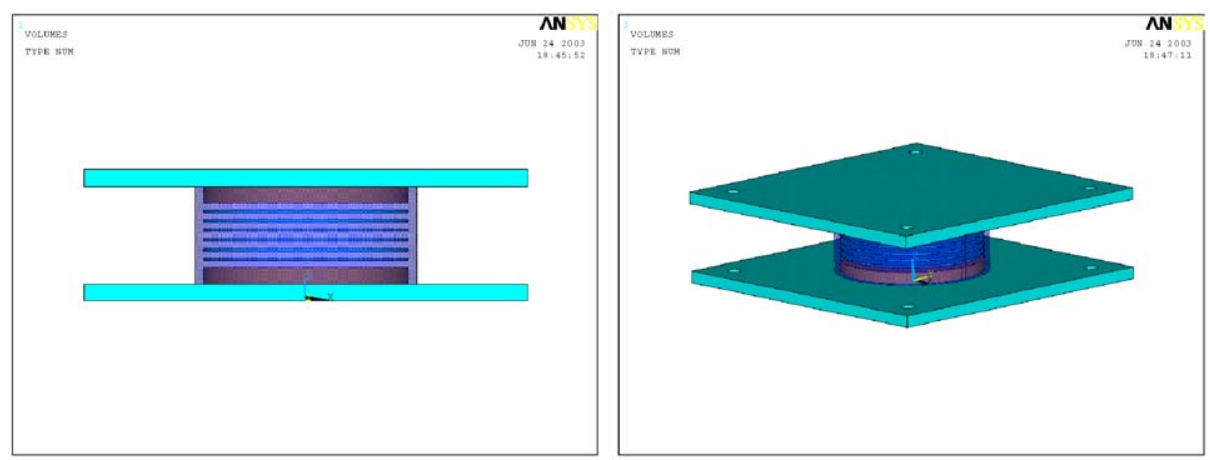

Fig. 2. Geometric layouts of steel rubber bearing used for vibration isolation of offshore jacket platform.

platform are shown in Fig. 2. The main part of the steel rubber bearing is designed as a cylinder, and two primary shape factors are defined as follows:

$S_{1}=\frac{\text { compressive surface }}{\text { free surface }}=\frac{D}{4 t_{R}}$

$S_{2}=\frac{\text { diameter of rubber }}{\text { total thickness of rubber layers }}=\frac{D}{n t_{R}}$

where $D$ is the diameter of rubber sheet, $t_{R}$ is the thickness of rubber layer and $n$ is the number of rubber layers.

Assume that $\delta_{H}$ is the relative horizontal displacement, $\varepsilon_{m}$ is the total shear strain, which is the sum of two parts: $\gamma_{s}$ induced by horizontal distortion and $\gamma_{c}$ induced by compressive distortion.

$\varepsilon_{m}=\gamma_{s}+\gamma_{c}, \quad \gamma_{s}=\frac{\delta_{H}}{n t_{R}}, \quad \gamma_{c}=6 S_{1} \varepsilon_{c}$

where

$\varepsilon_{c}=\frac{P_{v}}{A_{e}} \frac{1}{3 G\left(1+2 \kappa S_{1}^{2}\right)}$

$A_{e}$ is the effective area, a superposition of the projections of upper surface and base surfaces.

$A_{e}=A\left\{1-\frac{2}{\pi}\left[\frac{\delta_{H}}{D} \sqrt{1-\left(\frac{\delta_{H}}{D}\right)^{2}}+\sin ^{-1}\left(\frac{\delta_{H}}{D}\right)\right]\right\}$

and $A$ is the original upper/base surface area. $G$ is the shear modulus of rubber. $\kappa$ is a correction coefficient of rubber, obtained from laboratory test.

The total shear strain $\varepsilon_{m}$ can be computed by the following approximate formulas:

$A_{e} \approx A, \quad \sigma \approx \frac{P_{v}}{A}, \quad 1+2 \kappa S_{1}^{2} \approx 2 \kappa S_{1}^{2}$

then we have

$\varepsilon_{m}=\frac{\delta_{H}}{n t_{R}}+\frac{\sigma}{G \kappa S_{1}}$

The primary parameters of prototype steel rubber bearing are listed in the following Table 1

The horizontal displacement range and $\gamma_{s}$ is

$\delta_{H}=30-50 \mathrm{~mm}, \quad \gamma_{s}=\frac{\delta_{H}}{n t_{R}}=50-80 \%$

The vertical compressive stress range and $\gamma_{c}$ are, respectively,

$\sigma_{p}=10-15 \mathrm{MPa}, \quad \gamma_{c}=\frac{\sigma}{G \kappa S_{1}}=140-160 \%$
Table 1

Primary parameters of the rubber bearing.

\begin{tabular}{llll}
\hline Rigidity $( \pm 2)$ & $G / \mathrm{MPa}$ & $\kappa$ & $E_{b} / \mathrm{MPa}$ \\
\hline 40 & 0.46 & 0.85 & 2040 \\
\hline
\end{tabular}

The following are the geometrical data of the prototype steel rubber bearing:

Thickness of rubber sheet:

Number of rubber layers:

Thickness of rubber layers:

Diameter of rubber $D$ :

Primary shape factors $S_{1}, S_{2}$ :
$t_{R}=6-7 \mathrm{~mm}$

$n=10$

$60-70 \mathrm{~mm}$

$800-1000 \mathrm{~mm}$

$S_{1}=16-18$

\subsection{Specifications and geometric data of the scale model of steel rubber bearing}

In this paper, we study two groups of testing bearings, each with two scale models of steel rubber bearing. The first group is used to study the compressive properties and the second group is for fatigue tests in cold environment. Specifications and geometric data of the scale model of the steel rubber bearing are as follows.

The following are the geometrical data of the scale model:

$\begin{array}{ll}\text { Thickness of rubber sheet: } & t_{R}=4 \mathrm{~mm} \\ \text { Number of rubber layers: } & N=7 \\ \text { Thickness of rubber layers: } & 28 \mathrm{~mm} \\ \text { Thickness of steel plate: } & 1.5 \mathrm{~mm} \\ \text { Number of steel plates: } & 6 \\ \text { Diameter of rubber } D: & 120 \mathrm{~mm} \\ \text { Outer protective layer } & 5 \mathrm{~mm} \\ \text { Primary shape factors } S_{1}, S_{2}: & 7.5,4.28 \\ \text { Upper and base steel plates: } & 260 \mathrm{~mm} \times 260 \mathrm{~mm} \times 10 \mathrm{~mm}(2 \text { pieces) } \\ \text { Total thickness of steel rubber bearing: } & 77 \mathrm{~mm}\end{array}$

\section{Pre-compression and shear load fatigue experiment and the corresponding equipment in cold environment}

\subsection{Test facilities}

Various mechanical properties of this kind isolator cannot be easily obtained by computation or theoretical analysis. Especially, the fatigue properties must be obtained by tests in laboratory or in actual operations.

In this paper, we seal up an annular inner space along the bearing between the upper and base steel plates for the first group 
a

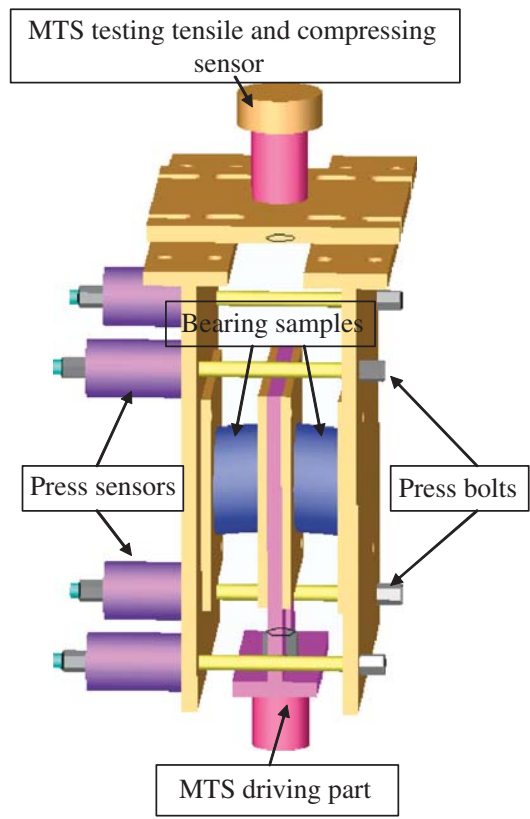

b

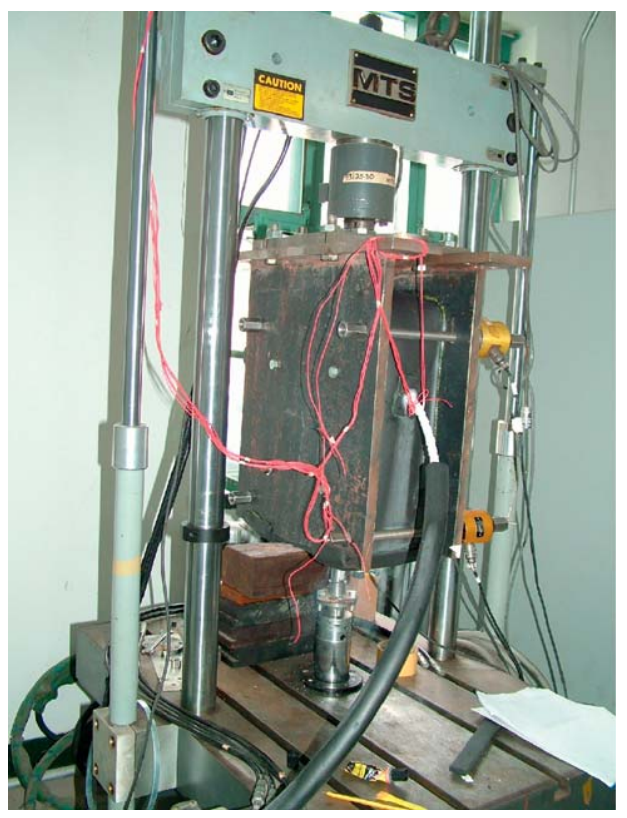

Fig. 3. Test facility (a) Geometric layouts of fatigue test facility. (b) Layouts of fatigue test facility in cold environment.

of scale model to carry out the compressive test. The fatigue test facility is shown in Fig. 3(a) and an inner space incasing the two bearings between flank plates is sealed up as shown in Fig. 3(b). The pipe connecting the inner space and the bottle of fluid nitrogen is used to feed the nitrogen to refrigerate the inner space and on the other side we have a vent. The vertical compressive force $p_{e}$ is distributed evenly by screwing down the four bolts. The horizontal shear force is driven by MTS as a sine wave force by control the horizontal displacement $\mp \delta_{H e}$.

\subsection{Test procedures (see Fig. 3)}

1. Start up MTS.

2. Hanging up the coping and two flank plates to MTS, without screwing down the connecting bolts for a while.

3. Install two steel rubber bearings on the flank plates, a mid plate between the bearings, and screw down the connecting bolts.

4. Seal up an inner space along the specimen, after the glue clings adequately, install the link bar between the mid plate and MTS driving part.

5. Install four press sensors and four press bolts, and then screw down the bolts until each compressive force is as required.

6. Screw down all connecting bolts.

7. Connect the pipe for feeding the nitrogen.

8. When the temperature of the inner space reaches the target value, keep it for 1-2 h, and operate MTS to begin fatigue test.

\subsection{Fatigue test case}

The primary parameters of group 1 are the same as the prototype shown in Table 1 , and the scale model must have the same shear strain.

Let $\gamma_{c e}=\sigma /\left(G \kappa S_{1}\right)=160 \%$ and $\gamma_{s e}=\delta_{H} / n t_{R}=50 \%$, we have

$\sigma_{e}=\gamma_{c e} G \kappa S_{1}=160 \% \times 0.46 \times 0.85 \times 7.5=4.692 \mathrm{MPa}$

$$
\begin{aligned}
& P_{e}=\sigma_{e} A=4.692 \times \frac{\pi}{4} D^{2}=53.065(\mathrm{KN})=5.3(\mathrm{~T}) \\
& \delta_{\mathrm{He}}=\gamma_{s e} n t_{R}=50 \% \times 7 \times 4=14(\mathrm{~mm})
\end{aligned}
$$

\section{Experimental results and discussion}

The fatigue test frequency is set as $2.5 \mathrm{~Hz}$. In the following test, we are mainly to investigate the changing of compressing stiffness with different temperatures and shear stiffness before-and-after the fatigue test in a cold environment, especially, the shear stiffness.

\subsection{Compressive properties and shear stiffness of group 1}

In this section, we discuss the compressive properties and shear stiffness under different temperatures. For each temperature point, the temperature holds for about $1 \mathrm{~h}$ before the test.

Figs. 4 and 5 show the relationship between compressive force and displacement of the two scale model bearings of group 1 . The curves can be seen as consisting of two parts. In the first part, the displacement increases rapidly when the compressive force increases from 0 to $1 \mathrm{t}$, and in the second part, the compressive stiffness (the slope of the curve) keeps almost unchanged for all temperatures. Fig. 4 shows that the displacement increases more rapidly in lower temperatures in the first part. It may be due to inner spaces through shrinking of rubber and steel. These phenomena do not affect the use of steel rubber bearing as an isolator in practical offshore jacket platform, because the isolators are working in a self-adjusted pre-compression environment and it is only required that the bearings match each other in one isolation layer.

Fig. 6 shows the relationship between shear force and shear displacement of group 1 with a slight increase of the shear stiffness when the temperature decreases. Each curve is plotted based on the average results of two repeated tests. 
a

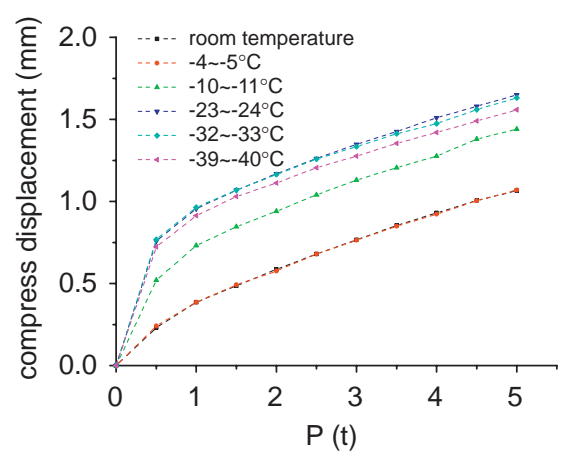

b

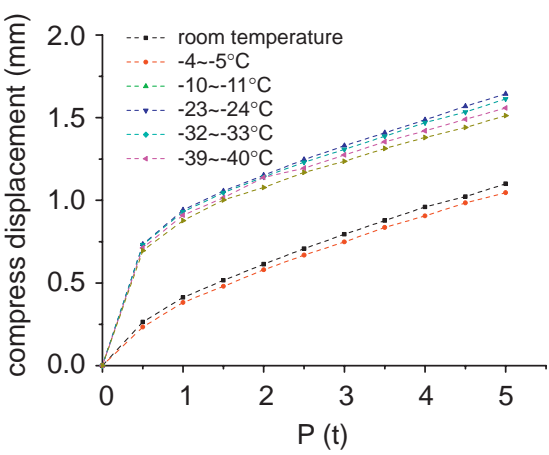

Fig. 4. The relationship between compressive force and displacement of scale model bearing 1 of group 1 (a) First compressive test. (b) Second compressive test.

a

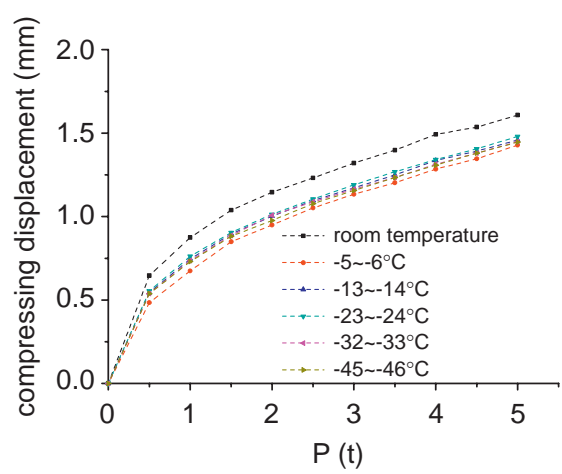

b

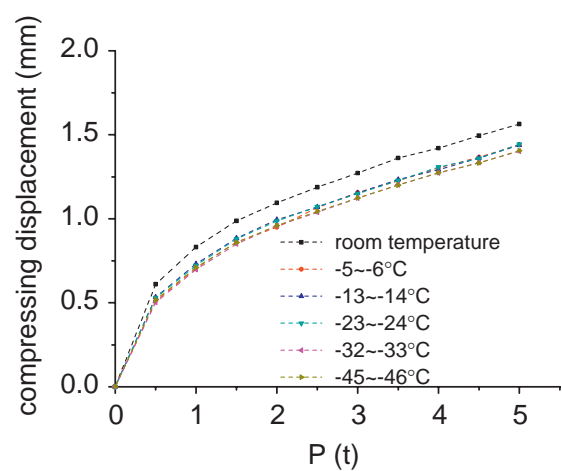

Fig. 5. The relationship between compressive force and displacement of scale model bearing 2 of group 1. (a) First compressive test. (b) Second compressive test.

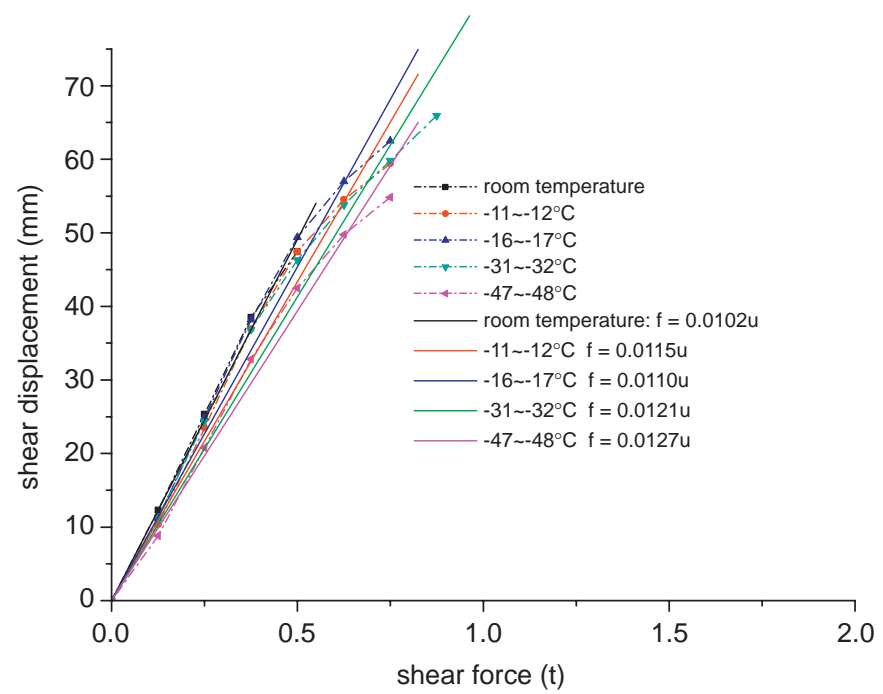

Fig. 6. The relationship between shear force and shear displacement of group 1.

\subsection{Pre-compression and shear load fatigue experiment in cold environment}

A 300,000 cycle fatigue was carried out in cold environment to obtain the fatigue properties of steel rubber bearings of group 2 , especially, the shear stiffness before-and-after a certain number of fatigue cycles. Table 2 lists a random sampling of pre-compressions and temperatures in the whole fatigue test.

Fig. 7 shows the shear properties before-and-after a certain number of fatigue cycles in cold environment, namely, beforeand-after the beginning of fatigue test, at 100,000 fatigue cycles,
Table 2

The pre-compressions and temperatures in the 300,000 fatigue cycles.

\begin{tabular}{llll}
\hline $\begin{array}{l}\text { Fatigue cycles } \\
\left(10^{4}\right)\end{array}$ & $\begin{array}{l}\text { Upper pre-compression } \\
(\mathrm{KN})\end{array}$ & $\begin{array}{l}\text { Lower pre-compression } \\
(\mathrm{KN})\end{array}$ & $T\left({ }^{\circ} \mathrm{C}\right)$ \\
\hline 0.184 & 54.0641 & 49.49359 & \\
2.477 & 53.85256 & 51.67949 & -41 \\
2.754 & 53.07051 & 50.10256 & -44.5 \\
3.89 & 53.75641 & 50.42949 & -39.5 \\
5.961 & 53.61538 & 51.16667 & -43.5 \\
7.806 & 51.64103 & 43.73077 & -38 \\
9.05 & 49.37821 & 44.69872 & -45 \\
10 & 42.32692 & 40.28846 & -52 \\
11.246 & 50.00641 & 47.85897 & -44 \\
12.274 & 44.40385 & 42.5641 & -44.5 \\
14.067 & 47.32692 & 44.75 & -43 \\
15.54 & 51.16667 & 48.10256 & -35.5 \\
16.276 & 51.79487 & 48.46795 & -34 \\
17.288 & 48.71154 & 44.28205 & -42 \\
18.767 & 44.37821 & 41.8141 & -46 \\
20 & 39.94231 & 37.09615 & -33 \\
21.824 & 51.167 & 49.385 & -38 \\
23.365 & 41.019 & 38.955 & -46.5 \\
24.445 & 49.295 & 47.429 & -44 \\
25.986 & 49.327 & 46.763 & -36 \\
26.66 & 48.462 & 46.846 & -28 \\
28.002 & 45.282 & 42.359 & -44.5 \\
30 & 36.673 & 34.231 & -40 \\
& & & -46.5 \\
\hline & & & \\
\hline
\end{tabular}

200,000 fatigue cycles and 300,000 fatigue cycles. The slope of the linearly fitted line is the average stiffness, and each curve is based on the average results of two repeated tests. Table 3 shows a comparison of the shear stiffness between fatigue tests in room 


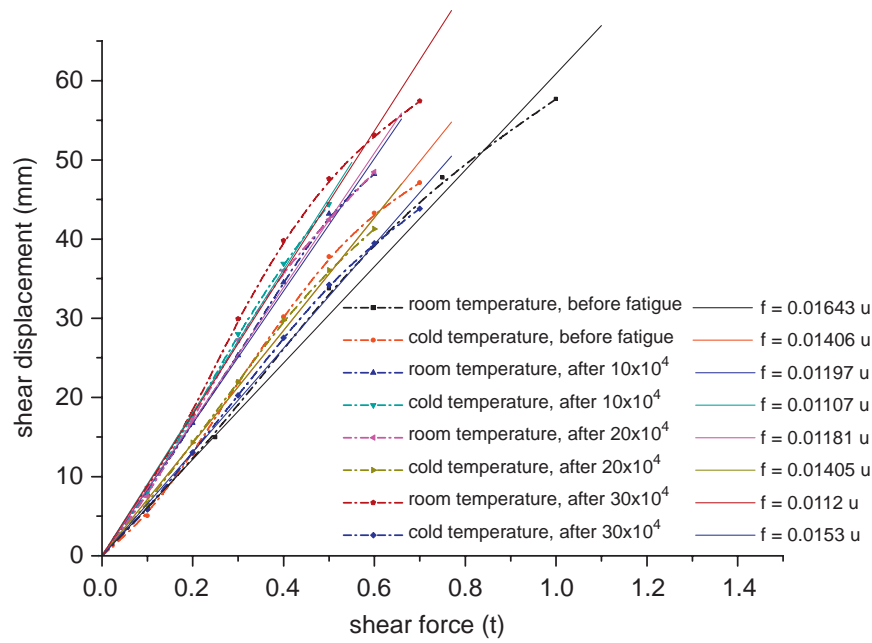

Fig. 7. The shear property before-and-after a certain number of fatigues cycles in cold environment.

Table 3

A comparison of the shear stiffness before-and-after a certain number of fatigue test.

\begin{tabular}{|c|c|c|c|c|c|c|}
\hline \multirow{3}{*}{$\begin{array}{l}\text { Fatigue } \\
\text { cycles }\left(10^{4}\right)\end{array}$} & \multirow{2}{*}{\multicolumn{2}{|c|}{$\begin{array}{l}\text { Room temperature } \\
\text { fatigue }\end{array}$}} & \multicolumn{4}{|c|}{ Cold environment fatigue } \\
\hline & & & \multicolumn{2}{|c|}{$\begin{array}{l}\text { Room temperature } \\
\text { stiffness }\end{array}$} & \multicolumn{2}{|c|}{ Cold stiffness } \\
\hline & $\begin{array}{l}\text { Shear } \\
\text { stiffness }\end{array}$ & $\begin{array}{l}\text { Reduction } \\
(\%)\end{array}$ & $\begin{array}{l}\text { Shear } \\
\text { stiffness }\end{array}$ & $\begin{array}{l}\text { Reduction } \\
(\%)\end{array}$ & $\begin{array}{l}\text { Shear } \\
\text { stiffness }\end{array}$ & $\begin{array}{l}\text { Reduction } \\
(\%)\end{array}$ \\
\hline 0 & 0.0120 & & 0.0164 & & 0.0141 & 14.41 \\
\hline 10 & & & 0.0120 & 27.16 & 0.0111 & 32.62 \\
\hline 20 & 0.0104 & 13.3 & 0.0118 & 28.13 & 0.0140 & 14.48 \\
\hline 30 & 0.0088 & 26.67 & 0.0112 & 31.94 & 0.0153 & 7.14 \\
\hline
\end{tabular}

temperature and in cold environment, and between stiffness tests in room temperature and in cold environment. From Table 3 we can see that the shear stiffness is reduced by about $26-32 \%$ after a certain fatigue cycles test, but most of reduction occurs in the first 100,000 fatigue cycles in the cold environment fatigue test. The stiffness tests show different features, which are carried out also in the same cold environment, the results are compared with those in room temperature environment. The shear stiffness of the first two sampling results shows some decrease, which may be caused by inner spaces induced by the different shrinking of rubber and steel. But we cannot explain why the last two results of 200,000 and 300,000 fatigue cycles test give some increase in shear stiffness. These phenomena will be explained by more tests in the future.

\section{Conclusions}

In this paper, the experimental test facility based on MTS is designed to carry out the pre-compression and shear load fatigue test of the steel rubber bearing used for vibration isolation of offshore jacket platform in cold environment. For the experimental results we may draw the following conclusions.

1. The compressive property variation sees two different phases. In the first phase, the displacement increases rapidly while the compressive force increases from 0 to $1 \mathrm{t}$, and in the second phase, the compressive stiffness keeps almost unchanged for all temperatures.

2. The displacement increases more rapidly in lower temperatures in the first phase, which may be caused by inner spaces induced by the different shrinking of rubber and steel in cold environment.

3. The above phenomena do not affect the use of steel rubber bearing as an isolator in practical offshore jacket platform, because the isolators are working in a self-adjust precompression environment, and the bearings are only required to match each other in the isolation layer.

4. The shear stiffness reduces about $26-32 \%$ after 300,000 fatigue cycles test, but most of the stiffness reduction occurs in the first 100,000 fatigue cycles in cold environment fatigue test.

5. The stiffness tests show different features, which are carried out also in the same cold environment. Compared with the case of room temperature environment, the shear stiffness of the first two sampling results shows some decrease, which may be caused by inner spaces induced by the different shrinking of rubber and steel.

6. We cannot give explain why the last two sampling results of 200,000 and 300,000 fatigue cycles give some increase in shear stiffness, and these phenomena will be explained by more tests in the future.

The experimental investigation provides some guidelines for design of steel rubber vibration isolator used for offshore platform in cold environment, and also for maintenance and replacement of steel rubber vibration bearings, and a basis for fatigue life assessment of the steel rubber vibration isolator.

\section{Acknowledgment}

This work was supported by the $863 \mathrm{Hi}$-tech Research and Development Program of China.

\section{References}

Abdel-Rohman, M., 1996. Structural control of steel jacket platform. Structural Engineering and Mechanics 4, 25-38.

Garcia, L.D., Soong, T.T., 2002. Efficiency of a simple approach to damper allocation in MDOF structures. Journal of Structural Control 9, 19-30.

Kawano, K., 1993. Active control effects on dynamic response of offshore structures. In: Proceedings of the Third ISOPE Conference 3, pp. 494-498.

Kawano, K., Venkataramana, K., 1992. Seismic response of offshore platform with TMD. Proceedings of the 10th World Conference on Earthquake Engineering 4, pp. 2241-2246.

Lee, H.H., 1997. Stochastic analysis for offshore structures with added mechanical dampers. Ocean Engineering 24, 817-834.

Liu Yubiao, Xu Yongjun, Kan Changzhen, Shi Zhongmin, 2006. Experimental research on fatigue properties of steel rubber vibration isolator for offshore jacket platform, (submitted to: An International Journal China Ocean Engineering).

Mahadik, A.S., Jangid, R.S., 2003. Active control of offshore jacket platforms. International Ship building Progress 50, 277-295.

Ou, Jinping, Long, Xu, Xiao, Yiqing, Wu, Bin, 2002. Damping isolation system and its vibration-suppressed effectiveness analysis for offshore platform jacket structures. Earthquake Engineering and Engineering Vibration 22 (3), 115-122 (in Chinese).

Patil, K.C., Jangid, R.S., 2005. Passive control of offshore jacket platforms. Ocean Engineering 32, 1933-1949.

Suneja, B.P., Datta, T.K., 1998. Active control of ALP with improved performance function. Ocean Engineering 25, 817-835.

Suneja, B.P., Datta, T.K., 1999. Nonlinear open-close loop active control of articulated leg platform. International Journal of Offshore and Polar Engineering 9, 141-148.

Tian, Q.L., Wong, C.W., 1990. Dynamic analysis of structures with frictional BAE isolator by the incremental harmonic balance method. In: Proceedings of the I. C. V. P. E. 90' voc. 1, pp. 27-32, Wuhan, China. 
Wang, S., 2002. Semi-active control of wave-induced vibration for offshore platforms by use of MR damper. International Conference on Offshore Mechanics and Artic Engineering, Oslo, Norway, June, pp. 23-28.

Wu, Yi Min, Samali, Bijan, 2002. Engineering Structures 24, 1203-1215.

Woo-Jung, Chung, Chung-Bang, Yun, Nam_Sik, Kim, Ju-Won, Seo, 1999. Shaking table and pseudodynamic tests for the evaluation of the seismic performance of base-isolated structures. Engineering Structures 21, 365-379.
Yu, Yousheng, Wang, Yan, 2005. The principle of damping isolation to reduce vibration and the effectiveness analysis of vibration-suppressed for offshore jacket structures. Journal of Qingdao Institute of Architecture and Engineering 26 (1), 40-43 (in Chinese). 